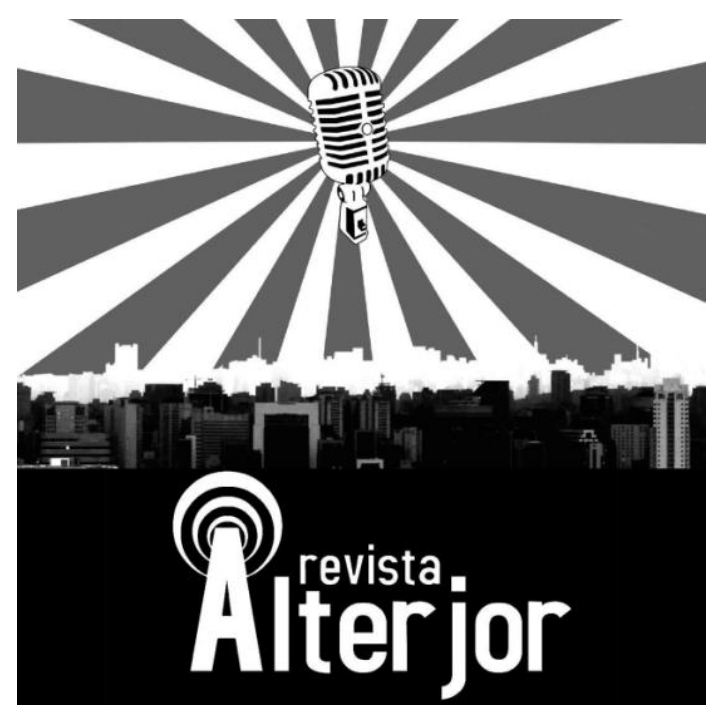

\title{
APOCALIPSE CARIOCA: PESTE, GUERRA, FOME E MORTE NO NOTICIÁRIO
}

\author{
Gabriela Nóra ${ }^{1}$ \\ Débora Mesquita ${ }^{2}$ \\ Mariana Souza ${ }^{3}$ \\ Ramon Andrade ${ }^{4}$
}

\begin{abstract}
RESUMO: O presente artigo é resultado de uma pesquisa mais ampla que se propõe a investigar como o noticiário carioca utiliza o aspecto negativo como principal critério de noticiabilidade. O "Jornalismo Construtivo" preconiza uma nova forma de abordagem das notícias pautado na função social do jornalismo, entendendo que deve-se ir além de apenas tornar público um problema, mas também munir sua audiência de informações inspiradoras que foquem em possíveis soluções. A partir desse conceito, a hipótese central deste trabalho é a de que o ambiente apontado pela mídia pode causar pessimismo e provocar uma sensação de apatia diante de um cenário apocalíptico. Usando como metáfora os quatro cavaleiros do apocalipse bíblico - Peste, Guerra, Fome e Morte - como instrumento de análise, observa-se que as manchetes imprimem um tom de caos absoluto na cidade.
\end{abstract}

PALAVRAS-CHAVE: Jornalismo construtivo. Rio de Janeiro. critérios de noticiabilidade.

ABSTRACT: This article is the result of a larger research that aims to investigate how the local news in Rio de Janeiro uses the negative as major newsworthiness. Based on the social role of journalism, the "Constructive Journalism" assumes a new way to report the news, understanding that it's not only about sharing the problem but also providing to the audience inspiring stories that focuses on available solutions. From this concept, the main hypothesis of this work, therefore, is that the environment pointed out by the media can cause pessimism and an apathy sensation, setting up an apocalyptic scenario. Adopting the metaphor of the four knights of the biblical apocalypse - Plague, War, Hungry and Death - as an instrument of analysis, it is possible to assume that headlines ascribe an environment of chaos in the city.

KEYWORDS: Constructive Journalism. Rio de Janeiro. Newsworthiness.

\footnotetext{
Professora Adjunta de Comunicação Social da Escola de Comunicação ECO/UFRJ, pesquisadora CNPq, jornalista e membro do Laboratório de Estudos em Comunicação Comunitária (LECC) da ECO/UFRJ. E-mail: gabriela.nora@yahoo.com.br

2 Mestranda no Programa de pós-graduação EICOS - IP/UFRJ. Integrante dos grupos de pesquisa MEDIATIO: Núcleo Interdisciplinar de Mediações, Humanidades e Subjetividades e membro do Laboratório de Estudos em Comunicação Comunitária (LECC) da ECO/UFRJ. Bolsista da Coordenação de Aperfeiçoamento de Pessoal de Nível Superior - CAPES. E-mail: mesquittadebora@gmail.com

Jornalista formada pelo curso de Comunicação Social - Jornalismo da ECO/UFRJ e membro do Laboratório de Estudos em Comunicação Comunitária (LECC) da ECO/UFRJ. E-mail: mari-pj@ hotmail.com

${ }^{4}$ Estudante de Comunicação Social - Jornalismo da ECO/UFRJ, bolsista do Programa Institucional de Bolsa de Iniciação Científica (PIBIC - CNPq) e membro do Laboratório de Estudos em Comunicação Comunitária (LECC) da ECO/UFRJ. E-mail: andradniz@gmail.com
}

Revista ALTERJOR

Grupo de Estudos Alterjor:Jornalismo Popular e Alternativo (ECA-USP)

Ano 10 Volume 02 Edição $22 \quad$ Julho-Dezembro de 2020

Avenida Professor Lúcio Martins Rodrig̉ues, 443, Cidade Universitária, São Paulo, CEP: 05508-020 


\section{INTRODUÇÃO: A ótica do jornalista}

O que é notícia? Essa definitivamente não é uma pergunta simples com uma resposta única e objetiva. Ao longo da história do jornalismo e da comunicação, como um estudo social, muito se debateu a respeito dos critérios para julgar o que é ou não digno de ser veiculado de forma massiva.

O teórico da comunicação Nelson Traquina (2008), ao analisar os séculos XVI e XVII, momento do surgimento das primeiras "folhas volantes", que precederam os jornais modernos, identifica aquilo que seriam os "primeiros valores-notícia". Esses "valores-notícia" se relacionavam diretamente com os acontecimentos que eram impressos com maior frequência, em sua maioria os de cunho insólito, como milagres, acontecimentos fora do comum e catástrofes.

De acordo com o sociólogo John B. Thompson (1998), na Inglaterra do século XVII o primeiro jornal produzido e de publicação semanal já demonstrava interesse pelas notícias de cunho trágico, uma vez que se estabeleceu como uma importante fonte de informação a partir de uma cobertura regular da Guerra dos Trinta Anos. Na virada do século XVIII, por sua vez, Ben Singer (2004) afirma que, com a modernidade, os jornais ressaltavam a ideia de uma sociedade definida pelo medo e perigo. Além de notícias descritivas sobre atropelamentos e mortes ocasionais, os jornais também utilizavam ilustrações como formas de crítica social e "sensacionalismo comercializado". Como afirma o autor: "[...] a imprensa tinha um óbvio interesse comercial em retratar o mundo com um tom drástico. Afinal, o clamor público e emoções fortes, e não o realismo cotidiano rotineiro, vendiam jornais" (SINGER, 2004, p. 110).

Traquina (2008), analisando o contexto americano durante o século XIX, assinala o surgimento da chamada "pennypress", jornais como o New York Sun já

\footnotetext{
${ }^{5}$ Segundo Traquina (2005- 2008), por volta dos anos 1830 os jornais passam a ser encarados como um negócio que pode render lucro, tendo como objetivo final o aumento das tiragens. Os jornais objetivam oferecer informação, não propaganda e seu produto são as notícias, baseadas nos fatos. No entanto, Penny
} 


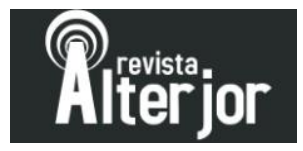

mostravam uma tendência a dar ênfase a notícias locais, histórias de crimes, tragédias e escândalos com enfoques sensacionalistas. A partir de sua pesquisa, o autor observa uma semelhança entre notícias de momentos diferentes da história, localizando esses elementos e posteriormente sistematizando as características que tais notícias carregavam. Traquina desenvolve um conceito de noticiabilidade, no qual "o conjunto de critérios e operações que fornecem a aptidão de merecer um tratamento jornalístico, isto é, possuir valor como notícia" (TRAQUINA, 2008, p. 63).

A definição dada pelo autor se aproxima do que é proposto por Mauro Wolf:

\begin{abstract}
A noticiabilidade corresponde ao conjunto de critérios, operações e instrumentos com os quais os aparatos de informação enfrentam a tarefa de escolher cotidianamente, de um número imprevisível e indefinido de acontecimentos, uma quantidade finita $\mathrm{e}$ tendencialmente estável de notícias (WOLF, 2008, p. 196).
\end{abstract}

Esses critérios utilizados para definir o que merece ou não ser transformado em conteúdo jornalístico dentro dos numerosos e complexos acontecimentos cotidianos são elencados por Traquina em "valores-notícia de seleção" e "valores-notícia de construção". Dentre os nove valores-notícia de seleção postulados pelo autor é interessante para o desenvolvimento de nosso estudo ressaltar os critérios substantivos de "morte", "infração", "conflito" e "escândalo".

O reconhecimento dos processos de gatekeeping $^{6}$ na elaboração da notícia explicita o caráter duvidoso das concepções romantizadas do jornalismo propostas pela

press, literalmente imprensa de centavos, passa a ter um contexto pejorativo como "imprensa barata", jornalismo com pouca qualidade.

${ }^{6}$ Gatekeeping é o termo dado ao processo de produção da informação. Segundo Traquina (2008), uma notícia para ser veiculada precisa passar por um fluxo, no qual há vários "portões", ou seja, áreas de decisão nas quais os jornalistas, ou gatekeepers, tem que decidir se tal notícia será publicada ou não. 
chamada Teoria do Espelho ${ }^{7}$ e abre espaço para um trabalho de análise em conjunto com outras linhas de estudo como as teorias de framing e agenda-setting ${ }^{8}$.

Erving Goffman (2012), um dos pioneiros na utilização da ideia de framing, assinala que quando se está em jogo diferentes interesses que produzem diferentes ênfases motivacionais, cada indivíduo apresenta perspectivas distintas para os “mesmos" acontecimentos e, por isso, estariam propensos a empregar aberturas e níveis de enfoque diferentes na hora de enquadrá-los.

A socióloga americana Gaye Tuchman (1993), por sua vez, refletindo sobre esses processos de produção da notícia afirma que os jornalistas invocam uma capacidade de difícil definição, em parte devido à forma como a cultura profissional privilegia um saber instintivo e não reflexivo. Em outras palavras, o jornalismo atua na inércia dos valores que historicamente são creditados como dignos de noticiabilidade e o que parece haver é uma falta de questionamento quantos a esses valores.

\section{"If it bleads, it leads": A negatividade como critério fundamental}

Mauro Wolf (2012) afirma que os valores-notícia obedecem a critérios relativos de noticiabilidade e apresenta a ideia de ideologia da informação, na qual o famoso ditado jornalístico "Bad news is good news ${ }^{10 "}$ se encaixa. Segundo tal ideologia, os leitores se sentem mais interessados por notícias que apresentem fatos que alterem a rotina, nos quais o de maior atenção são as infrações. Em seu capítulo "O newsmaking: critérios de relevância e 'noticiabilidade'", Wolf apresenta as ideias de Galtung e Ruge (1965), para reiterar a importância do negativo na produção de notícias: "Quanto mais um acontecimento for negativo nas suas consequências, maior será a probabilidade de

\footnotetext{
${ }^{7}$ Teoria que coloca o jornalista como um “comunicador desinteressado" e seu produto, as notícias, como um reflexo da realidade.

${ }^{8}$ Teoria de efeitos de longo prazo que propõe que a os meios de comunicação de massa não só tem o poder de incluir ou excluir assuntos da pauta da sociedade como também influenciam o que pensar sobre eles.

${ }^{9}$ Jargão jornalístico que teria como tradução aproximada: "Se sangra é lide"

${ }^{10}$ Tradução aproximada: "notícias ruins são boas notícias"
} 
se tornar notícia."(GALTUNG \& RUGE apud WOLF, 2012, p. 215)

Como previamente destacado, Nelson Traquina aponta que a morte é um valornotícia fundamental. O que constitui uma notícia não é um consenso entre os autores já citados, porém o uso do negativo como critério indispensável na produção de notícias parece ser unânime entre eles. Traquina sintetiza algumas justificativas que explicam o lugar de notoriedade que as notícias negativas ocupam dentro de um jornal, previamente apresentadas por Galtung e Ruge:

[...] a) as notícias negativas satisfazem melhor o critério de frequência; b) as notícias negativas são mais facilmente consensuais e inequívocas no sentido de que haverá acordo acerca da interpretação do acontecimento como negativo; c) as notícias negativas são mais consonantes com, pelo menos, algumas pré-imagens dominantes do nosso tempo; d) as notícias negativas são mais inesperadas do que as positivas, tanto no sentido de que os acontecimentos referidos são mais raros, como no sentido de que são menos previsíveis. (GALTUNG \& RUGE apud TRAQUINA, 2008, p. 72,73).

Como revelado pelos autores, elementos como o negativo, a morte e a infração são valores-notícia de expressiva importância. Vale ressaltar que a infração é entendida aqui como tudo aquilo que infringe a regra, logo dentro desta perspectiva o crime e a violência são considerados fenômenos importantes de serem noticiados, tanto pela sua frequência quanto pela sua permanência. $O$ fato de ser algo que interfere na vida cotidiana e de teor negativo faz com que o crime, num geral, seja artifício bem sucedido de veiculação de jornais.

Nota-se que ao longo da história do jornalismo, acontecimentos catastróficos, de cunho trágico, que geram fortes emoções no público e que focam no negativo, no conflito e na violência adquiriram um lugar central e praticamente indiscutível na definição de notícia. Fica evidente a massiva utilização de todos os elementos supracitados, mas essa empregabilidade excessiva de notícias trágicas pode curiosamente gerar uma falta de ressonância com o real e uma percepção distorcida da realidade - uma vez que só é dito aquilo que é negativo, sem saída, engajamento ou solução. Tendo em vista a relevância histórica e social da superexposição do negativo 


\section{Preierer}

nas páginas de jornais, no que diz respeito a adesão de leitores, surge a seguinte questão: quais os efeitos desta superexposição para os jornalistas, para a audiência e os seus impactos na cidade?

\section{O jornalismo na cidade do Rio}

A cidade do Rio Janeiro tem enfrentado uma sucessão de crises sem precedentes, documentadas cotidianamente por narrativas jornalísticas. Desvios milionários de verbas, abandono de hospitais, educação sucateada, ação de milícias, morte da vereadora Marielle Franco e seu motorista, Anderson Gomes, além de uma questionável intervenção (político) militar são alguns dos diversos exemplos que ilustram a situação da cidade. E não foram poucas as manchetes destinadas a estampar o permanente estado de caos que se instaurou no Rio de Janeiro.

Com o objetivo de entender com profundidade se de fato as notícias sobre a cidade do Rio de Janeiro são construídas por um viés negativo e pouco propositivo, foram investigadas as narrativas jornalísticas a partir de uma análise das matérias publicadas na editoria Rio do jornal O Globo ${ }^{11}$, de 22 de agosto de 2016 - data do encerramento dos jogos olímpicos na cidade - até o dia 6 de outubro de 2018 - data que antecede as eleições para a Presidência da República, governos estaduais, além dos cargos de senadores, deputados federais e deputados estaduais.

A análise foi realizada a partir da aplicação de um formulário desenvolvido para entender as questões centrais de cada notícia. Alguns dos itens analisados foram: a abordagem (negativa, positiva ou equilibrada), o conteúdo (interesse público ou irrelevante), se apresenta solução ou não, qual o foco da matéria, quais as questões centrais do lide e se a notícia apresentava ou não uma história inspiradora.

Como resultado, pode-se observar os gráficos abaixos, que demonstram que $67 \%$ das 6771 notícias analisadas apresentam uma abordagem negativa, mais de 5 mil

\footnotetext{
${ }^{11}$ Disponível em: < acervo.oglobo.globo.com> 


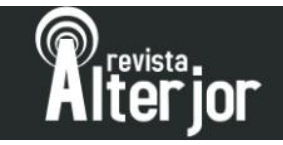

elas apresentam o foco em problemas e $76 \%$ das chamadas de capa de cada jornal tem foco no negativo, muitas vezes sensacionalista.

\section{ABORDAGEM}

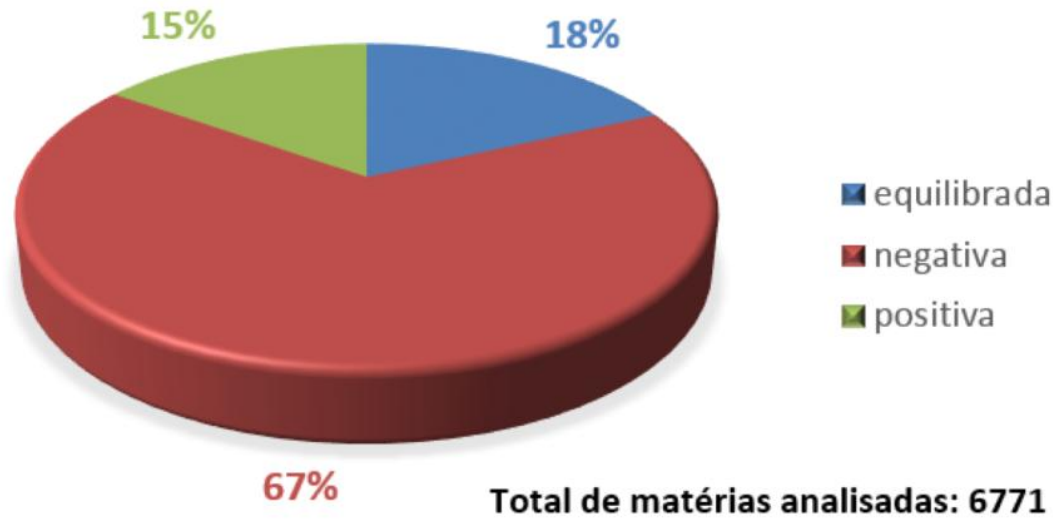

Gráfico 1: abordagem das notícias

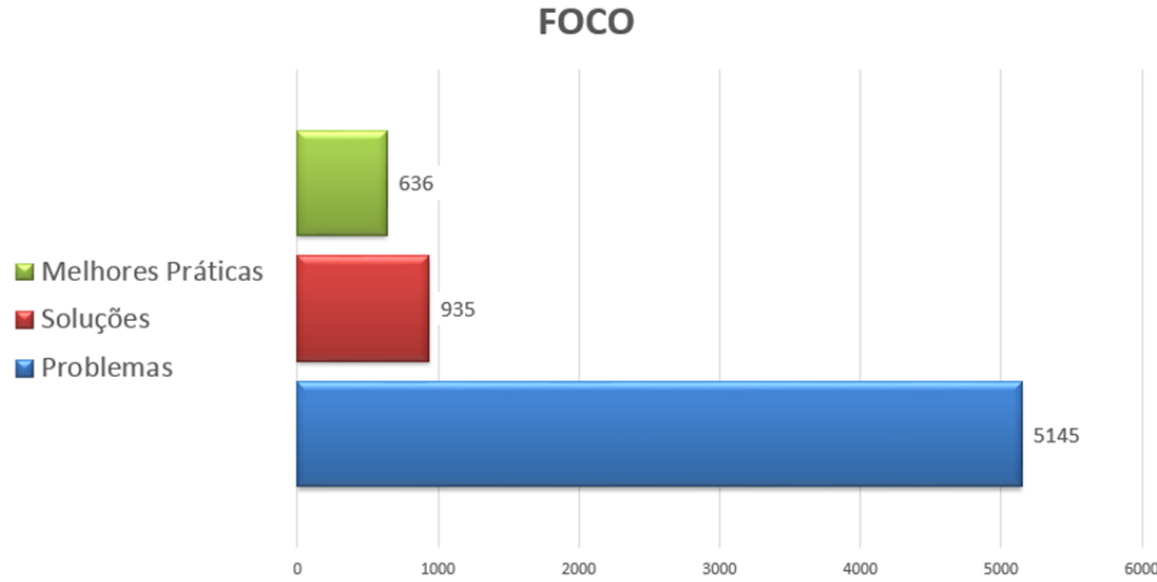

Gráfico 2: foco das notícias 


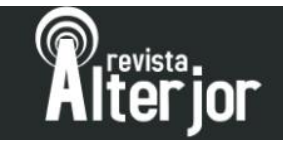

CHAMADA DE CAPA

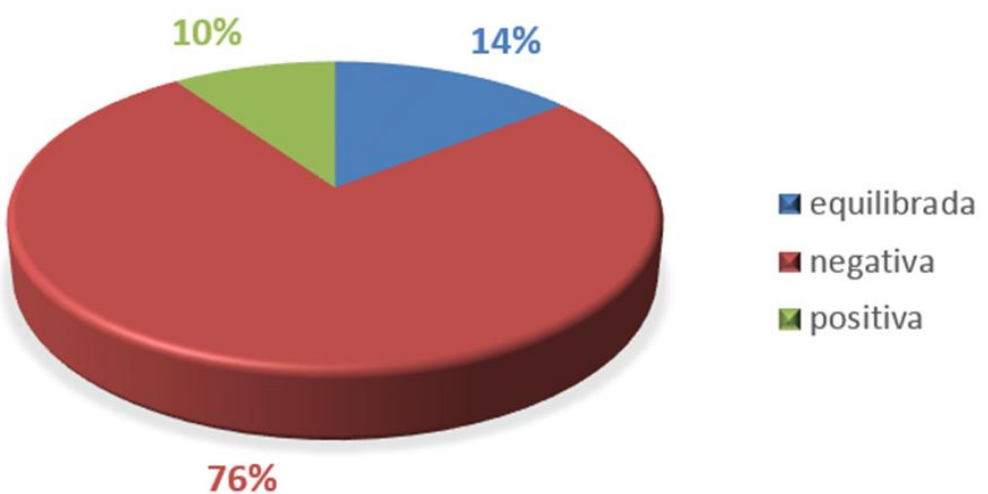

Gráfico 3: chamada de capa

\section{$O$ apocalipse carioca}

A partir da compreensão de que os conteúdos jornalísticos são narrativas que organizam e constroem realidades, buscou-se também investigar os discursos presentes nas matérias do jornal $\mathrm{O}$ Globo. Foi percebido, após análise dos dados, que o cenário apontado pelo jornal poderia sobrecarregar e oprimir a população, causando uma ideia trágica de uma conjuntura apocalíptica que desfavoreceria o engajamento social.

Susan Sontag $(2007,1989)$ em seu famoso ensaio "A doença como metáfora" e na sua continuação "Aids e suas metáforas" utiliza a metáfora como uma estratégia discursiva para elucidar seu pensamento a partir do conceito expresso por Aristóteles:

Por "metáfora" eu tinha em mente nada mais, nada menos do que a definição mais antiga e mais sucinta que conheço, que é a de Aristóteles, em sua Poética (1457b). "A metáfora", escreveu Aristóteles, "consiste em dar a uma coisa o nome de outra." Dizer que uma coisa é ou parece outra que não ela mesma é uma operação mental tão antiga quanto a filosofia e a poesia, e é a origem da maioria dos tipos de saber - inclusive o científico - e de expressividade. (SONTAG, 1989, p. 7)

Utilizando do mesmo artifício e a partir da metáfora bíblica dos quatro cavaleiros do apocalipse, Branco, Vermelho, Preto e Amarelo, representados 


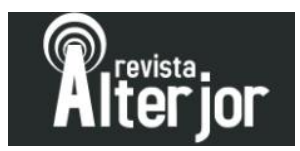

respectivamente pela Peste, Guerra, Fome e Morte, associamos cada "cavaleiro" a questões como: surtos de febre amarela, chikungunya, dengue; guerra entre traficantes e milícias; a crise financeira e cortes de verbas para a cultura e para investimentos; mortes pela violência e pelo descaso na saúde, respectivamente.

Notou-se que os próprios enunciados jornalísticos utilizavam-se de metáforas similares com finalidades dramáticas. As metáforas de guerra são as que mais chamam atenção, exaltando a violência e um estado de guerra constante, como se atesta nos exemplos a seguir: "Diário de uma guerra"" , "Tráfico em guerra: Sob artilharia pesada"13, "Cariocas na linha de tiro"", "Medicina de guerra: Situação de emergência"15.

Sontag propõe uma interessante leitura sobre tais metáforas: "De fato, a utilização da guerra como oportunidade para a mobilização ideológica em massa faz da ideia de guerra uma metáfora adequada para designar qualquer campanha cujo objetivo seja apresentado como a derrota de um inimigo" (SONTAG, 1989, p. 50). É muito significativo como os próprios enunciados jornalísticos foram utilizados para ratificar a extrema violência na cidade e legitimar o processo de intervenção militar ocorrido em 2018. Sontag também aborda como o pessimismo e a percepção de catástrofe se articula a ideia do novo, de começar do zero, totalmente presentes nos discursos pró-intervenção militar.

A vontade de fazer previsões pessimistas reflete a necessidade de dominar o medo do que é considerado incontrolável. Exprime também uma cumplicidade imaginativa com o desastre. A sensação de mal-estar ou fracasso cultural dá origem à vontade de começar do zero, de fazer tábula rasa. (SONTAG, 1989, p.84-85)

\footnotetext{
${ }^{12}$ Jornal O Globo, Editoria Rio, p.21, 27/01/18

13 . p.6, 29/10/17

$14 \longrightarrow$ p. $8,01 / 02 / 18$

$15+$ p. $10,25 / 01 / 17$
}

Revista ALTERJOR

Grupo de Estudos Alterjor:Jornalismo Popular e Alternativo (ECA-USP)

Ano 10 Volume 02 Edição $22 \quad$ Julho- Dezembro de 2020

Avenida Professor Lúcio Martins Rodrig̉ues, 443, Cidade Universitária, São Paulo, CEP: 05508-020 


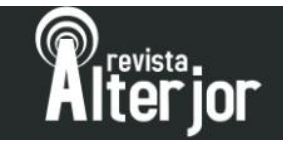

As demais metáforas, a "peste", a "fome" e a "morte", podem ser vistas nos exemplos a seguir: "Rio teve 44 crianças mortas a tiros nos últimos 11 anos" ${ }^{16}$, "Cofre vazio: Pacote desfigurado" 17, "Chicungunha: Número de casos no Rio sobe $14.000 \% " 18$. Pode-se identificar uma macronarrativa apocalíptica na qual as diversas narrativas veiculadas cotidianamente no jornal se articulam e acabam gerando pânico moral e uma sensação de caos absoluto. Praticamente metade das matérias veiculadas no período analisado se associavam de alguma forma com as metáforas propostas:

É possível também identificar que o jornal faz uso de títulos apelativos, imagens fortes e enunciados que se articulam diretamente com a sensação de medo e desordem. "O medo no caminho"19, "Do céu ao inferno",20 e "O êxodo da Rocinha"21, são alguns exemplos significativos.

\section{ABORDAGEM NEGATIVA - APOCALIPSE}

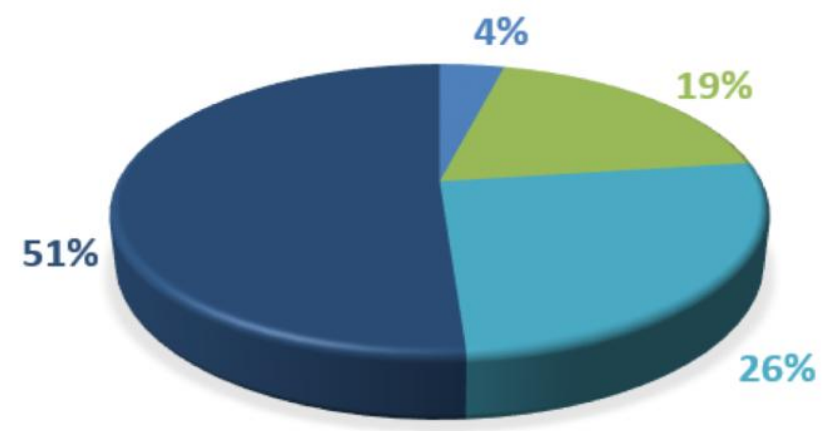

Gráfico 4: Abordagem das notícias com foco em "Peste", "Fome", "Guerra e Morte", "Outros".

Susan Sontag, refletindo sobre as metáforas em torno da Aids, propõe uma análise da retórica apocalíptica presente na sociedade moderna. Embora o objeto de

\footnotetext{
${ }^{16}$ Jornal O Globo, editoria Rio, p.9, 07/02/18

17

p. $23,01 / 12 / 16$

18 p.19, 25/11/16

19 CAPA, 07/02/18

20 p. $8,02 / 02 / 18$

21 p. $11,29 / 10 / 17$
}

Revista ALTERJOR

Grupo de Estudos Alterjor: Jornalismo Popular e Alternativo (ECA-USP)

Ano 10 Volume 02 Edição $22 \quad$ Juho- Dezembro de 2020

Avenida Professor Lúcio Martins Rodrig̉ues, 443, Cidade Universitária, São Paulo, CEP: 05508-020 
estudo da autora seja outro, sua observação é muito válida para elucidar a hipótese deste trabalho:

\begin{abstract}
A vida moderna nos habitua a conviver com a consciência intermitente de catástrofes monstruosas, impensáveis - porém, conforme nos afirmam, bem prováveis. Cada acontecimento importante tem seu duplo, além de sua representação enquanto imagem (uma duplicação já antiga da realidade, que começou com a invenção da câmara fotográfica, em 1839). Ao lado da simulação fotográfica ou eletrônica dos eventos, temos também o cálculo de suas consequências eventuais. A realidade bifurcou-se, na coisa real e em sua versão alternativa, duas vezes. Temos o evento e sua imagem. E temos o evento e sua projeção. Mas como para as pessoas os eventos reais muitas vezes não parecem ter mais realidade do que as imagens, nossas reações a eventos do presente recorrem, para confirmá-los, a esboços mentais, acompanhados de cálculos apropriados, do evento em sua forma projetada, final. (SONTAG, 1989, p.85)
\end{abstract}

Dentre as matérias analisadas, 94\% são constituídas de uma abordagem negativa e que não apresentam solução, são notícias apenas expositivas, que não propõem nenhum tipo de reflexão ou engajamento. Os efeitos do que poderíamos chamar de onipresença da negatividade na mídia já estão sendo notados. Uma pesquisa ${ }^{22}$ realizada pelo Instituto Reuters para o Estudo do Jornalismo divulgado em 2017 mostra um crescente afastamento do noticiário pelo público. Em $48 \%$ dos casos o afastamento se dá devido aos efeitos negativos sentidos no humor pelo público analisado e $37 \%$ dos entrevistados disseram não confiar no noticiário como sendo verdadeiro. Vale ressaltar também os $22 \%$ que afirmam que as fortes imagens afetam seu humor negativamente assim como os $28 \%$ que dizem que se sentem impotentes em relação ao que é mostrado pela mídia.

\title{
Jornalismo Construtivo
}

O trabalho tem como proposta central, após a análise das notícias e produção dos gráficos, sugerir uma mudança no modelo atual de produção de notícias. Por isso, foi investigado os preceitos de um novo modelo de jornalismo que prega uma abordagem

\footnotetext{
${ }^{22}$ Disponível em: <http://www.digitalnewsreport.org/survey/2017/news-avoidance-2017/> Acesso: $14 / 04 / 19$
}

Revista ALTERJOR

Grupo de Estudos Alterjor:Jornalismo Popular e Alternativo (ECA-USP)

Ano 10 Volume 02 Edição $22 \quad$ Juho- Dezembro de 2020

Avenida Professor Lúcio Martins Rodrig̉ues, 443, Cidade Universitária, São Paulo, CEP: 05508-020 


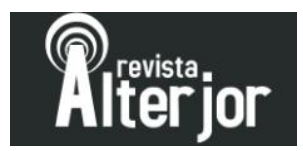

contextualizada e equilibrada (positivo/negativo), denominado "jornalismo construtivo". Nele, a elaboração de notícias estaria dentro do conceito de reportagens slow food, ou seja, haveria um incentivo à produção orientada para o futuro, com ênfase na solução de problemas. As narrativas jornalísticas seriam, nesse novo modelo proposto, mais do que fonte de informações cruas (como defende a teoria do espelho, já mencionada), forneceria inspiração para o engajamento de pessoas.

É entendido, a partir das teorias do jornalismo construtivo, que a função social do jornalismo não se resume em tornar público um problema, mas também está fortemente ligado à tentativa de procurar soluções viáveis para ele, além de facilitar o entendimento do público.

A psicóloga e escritora Jodie Jackson (2019) motivada a questionar os efeitos negativos das notícias elaborou um estudo sobre como o noticiário afeta o humor das pessoas, suas crenças e entendimento de mundo. Segundo a autora, a informação é para o cérebro o que a comida é para o corpo, e a forma como a realidade está sendo retratada pela mídia fomenta uma percepção de mundo equivocada, muitas vezes interferindo e manipulando decisões sociais e políticas na sociedade.

Para Jackson, a presença da mídia é tão bem estabelecida, que se tornou uma parte natural da democracia. A sociedade não tem o hábito de pensar criticamente sobre a interferência midiática, formando opiniões sem realmente saberem o porquê de pensarem como pensam. "Isso acontece porque as notícias são uma invisível porém poderosa influência em nossos pensamentos, nos dizendo não só o que pensar (decidindo o que será reportado) mas como pensar (através de cortes nas notícias e do viés organizacional)" (JACKSON, 2019, p. 3$)^{23}$.

Inspirado pelos mesmos questionamentos, o jornalista Ulrik Haagerup fundou, em 2017, o "Constructive Institute", uma organização sem fins lucrativos localizada na Aarhus University, na Dinamarca. Após anos imerso em uma cultura profissional voltada para a construção de notícias pouco propositivas e com foco no negativo,

\footnotetext{
${ }^{23}$ Tradução dos autores, a partir do texto original: "This is because the news is an invisible but powerful influence on our thoughts, telling us not only what to think about (by deciding what is reported) but also how to think about it (through news frames and organisational bias".
} 
Haagerup (2017) chama atenção para a necessidade de um jornalismo essencialmente de soluções, onde o foco não seria criar o que o autor chama de "falso senso de esperança", mas sim uma narrativa que consiga perceber o que de bom e/ou engajador pode-se tirar de uma notícia trágica.

Assim, o jornalismo construtivo não representa especulações ou narrativas esperançosas com tom utópico, mas prega a necessidade de uma investigação crítica e mais aguçada que não só informe os problemas da cidade, como consiga olhar além dele e tentar entender qual progresso ou ação social seria necessária para melhorá-los.

Ainda segundo Jodie Jackson, há algumas perguntas centrais que podem ajudar o jornalista na construção de notícias construtivas como: "Isto está funcionando? Como está sendo feito? Quais são as limitações? Isto é escalável? Podemos aprender algo através das soluções implementadas? Se eles estão falhando, qual é o problema?" (JACKSON, 2019, p. 80) ${ }^{24}$. A proposta construtiva acredita que ao informar soluções e possíveis ações de engajamento social, o sentimento de descrença e caos na cidade dão lugar a uma sensação positiva de melhorias futuras.

\section{E agora?}

Após a análise dos jornais e estudo aprofundado sobre as propostas do jornalismo construtivo, faz-se necessário indagar um questionamento acerca do que o noticiário sobre a cidade do Rio de Janeiro nos diz.

Como os relatos jornalísticos projetam a imagem da cidade interna e externamente, atuando diretamente sobre o imaginário que se tem dela? Quais os efeitos desta cobertura em termos de engajamento e impacto sobre as emoções do público e dos profissionais envolvidos? $\mathrm{E}$, finalmente, como reescrever as narrativas da cidade a partir de matérias construtivas? ${ }^{25}$

\footnotetext{
${ }^{24}$ Tradução dos autores, a partir do texto original: "We can ask questions like, is it working? How is it being done? What are the limitations? Is it scalable? Can we learn anything from the solutions being implemented? If they are failing, what is the problem?"

${ }^{25}$ NÓRA, Gabriela. "Jornalismo construtivo: em busca de soluções para a cidade e para o jornalismo". Projeto de Pesquisa do Laboratório de Estudos em Comunicação Comunitária, LECC-ECO-UFRJ, 2018.
} 


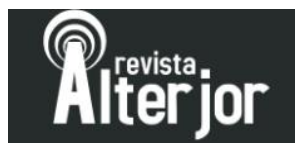

Diante do estudo teórico e histórico e a partir da pesquisa empírica realizada é notório afirmar que o jornalismo, não apenas na cidade do Rio de Janeiro, é pautado majoritariamente em notícias de cunho trágico e que exaltam os aspectos negativos dos fatos. Mas será que o atual modus operandi consegue cumprir totalmente o papel do jornalismo que seria o de fornecer o melhor panorama social munindo seu público com informações para um reflexão crítica dos fatos?

O que podemos observar é que há uma macronarrativa que exacerba o caos e o negativo provocando uma distorção de percepção entre o público. Não propomos que os fatos de cunho negativo relatados sejam omitidos, mas que haja uma proposição sobre o que fazer, quais caminhos especialistas no assunto propõem, para que despertar o senso de comunidade, de engajamento e para que toda a sociedade reflita e discuta de forma conjunta as problemáticas.

\section{REFERÊNCIAS BIBLIOGRÁFICAS}

SINGER, B. Modernidade, hiperestímulo e o início do sensacionalismo popular in CHARNEY, Leo \& SHWARTZ, Vanessa R. O cinema e a invenção da vida moderna. $2^{\text {a }}$ ed. São Paulo: Cosac Naify, 2004.

GALTUNG, J and RUGE, M. The Structure of Foreign News: The presentation of the Congo, Cuba and Cyprus crises four Norwegian newspapers. In.: WOLF, Mauro. Teoria das comunicações de massa. $6^{\text {a }}$ ed. São Paulo. WMF Martins Fontes, 2012, p. 215.

GOFFMAN, Erving. Os quadros da experiência social: uma perspectiva de análise. Petrópolis: Editora Vozes, 2012.

HAAGERUP, Ulrik. Constructive news. Dinamarca: Aarhus University Press, 2017.

JACKSON, J. You are what you read. Grã Bretanha. $1^{\text {a }}$ ed.Editora: CPI Group, 2019.

SONTAG, Susan. A Doença como Metáfora. São Paulo: Companhia das Letras, 2007. Aids e Suas Metáforas. São Paulo: Companhia das Letras, 1989.

THOMPSON, John B. Mídia e Modernidade, uma teoria social da Mídia. $5^{\text {a }}$ ed. Petrópolis, Rio de Janeiro: Vozes, 1998.

TRAQUINA, Nelson. Teorias do Jornalismo, Volume I: Porque as notícias são como são. 2.ed. Florianópolis: Insular, 2005.

Teorias do jornalismo Volume II - A tribo jornalística - uma comunidade interpretativa transnacional. $2^{\mathrm{a}}$ ed. Florianópolis: Insular, 2008.

Revista AL TERJOR

Grupo de Estudos Alterjor:Jornalismo Popular e Alternativo (ECA-USP)

Ano 10 Volume 02 Edição $22 \quad$ Juho- Dezembro de 2020

Avenida Professor Lúcio Martins Rodrig̉ues, 443, Cidade Universitária, São Paulo, CEP: 05508-020 


\section{Retiejor}

TUCHMANN, Gaye. A objetividade como ritual estratégico: uma análise das noções de objetividade dos jornalistas. In.: TRAQUINA, Nelson (org.) Jornalismo - questões, teorias e "estórias". Lisboa: Vega, 1993, p. 74-90.

WOLF, Mauro. Teoria das comunicações de massa. $6^{\mathrm{a}}$ ed. São Paulo. WMF Martins Fontes, 2012. 